\title{
SOCIAL ROLE DYSFUNCTION AND COPING IN BORDERLINE PERSONALITY DISORDER
}

\author{
by \\ Emma M. Carlson \\ B.Sc., Simon Fraser University, 2016 \\ A THESIS SUBMITTED IN PARTIAL FULFILLMENT OF \\ THE REQUIREMENTS FOR THE DEGREE OF
}

MASTER OF ARTS

in

THE FACULTY OF GRADUATE AND POSTDOCTORAL STUDIES

(Counselling Psychology)

THE UNIVERSITY OF BRITISH COLUMBIA

(Vancouver)

November 2019

(C) Emma M. Carlson, 2019 
The following individuals certify that they have read, and recommend to the Faculty of Graduate and Postdoctoral Studies for acceptance, a thesis entitled:

Social role dysfunction and coping in borderline personality disorder

submitted by Emma M. Carlson in partial fulfillment of the requirements for

the degree of Master of Arts

in

Counselling Psychology

\section{Examining Committee:}

Daniel W. Cox, Counselling Psychology

Supervisor

David Kealy, Psychiatry

Supervisory Committee Member

Alexander Chapman, Psychology, Simon Fraser University

Supervisory Committee Member 


\begin{abstract}
Individuals with borderline personality disorder (BPD) often experience deficits in social role performance, which encompasses the ability to adhere to socially defined rules and norms of behaviour. Additionally, research suggests that coping styles influence the way individuals with BPD manage stress, and that overall symptom severity and functioning in individuals with BPD varies across genders. This study sought to explore these variables via moderated mediation, investigating the mediating influence of coping styles on the relationship between BPD symptoms and social role dysfunction, and if these association were further moderated by gender. Participants $(N=233)$ were outpatients attending an intensive group treatment program who completed self-report measures on personality dysfunction, coping styles, and social role functioning. A moderated mediation model shows that for women with high BPD symptoms, usage of emotion-oriented coping was associated with increased social role dysfunction. Interestingly, also for women with high BPD symptoms, decreased use of social diversionoriented coping was associated with increased social role dysfunction. No significant associations were found between coping and social role dysfunction among men. Findings suggest that social support seeking and a healthy social network may play an important part in the ongoing social development of women with BPD. From this, potential early therapeutic interventions targeting safe social engagement in times of stress may decrease the pervasive and persistent nature of social dysfunction in BPD.
\end{abstract}




\section{Lay Summary}

Borderline personality disorder (BPD) poses serious health concern, and diagnoses are rising in both clinical and non-clinical populations. Individuals with BPD often have trouble experiencing and managing emotions and can show a pattern of unstable and strained interpersonal relationships. Social difficulties have been found to outlast other problems experienced by individuals with BPD, and these individuals show deficits performing the normal tasks associated with social roles, such as employee, romantic partner, or parent. With this study, we wanted to show how the way that these individuals cope with stress influences how they engage with others socially. We found that women who coped with stress using more emotional methods, such as crying, or less social distraction experienced more difficulty in their social role functioning. No patterns were found for men. This research shows that seeking helpful social support may be an effective way for individuals with BPD to improve social interactions. 


\section{Preface}

This thesis is the original and unpublished work by the author, Emma M. Carlson. Data for this thesis was originally collected as part of a larger study conducted at the University of Alberta, and was approved by the University of Alberta Ethics Board (B-040601-MED) and the University of British Columbia Board of Research Ethics (B00-0522). None of the text of this thesis is taken from previously published or collaborative articles. Statistical support and manuscript edits were provided by Dr. Daniel W. Cox, Dr. David Kealy, and Dr. Alexander Chapman. 


\section{Table of Contents}

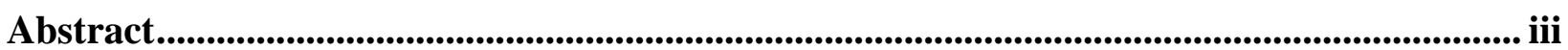

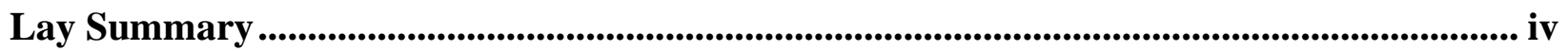

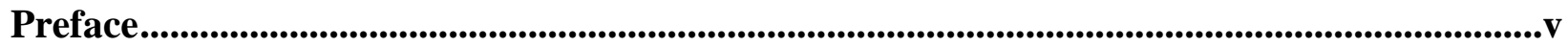

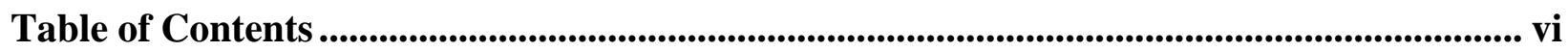

List of Tables ............................................................................................................................................. viii

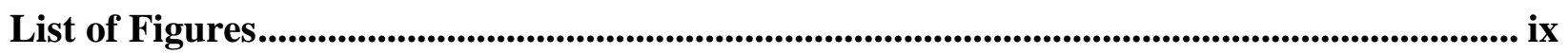

List of Abbreviations ........................................................................................................................................

Acknowledgements ........................................................................................................................................ xi

Chapter 1: Introduction ..........................................................................................................................................1

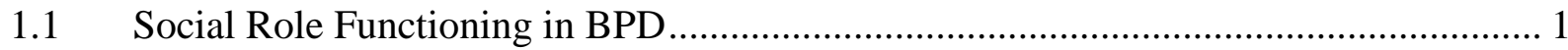

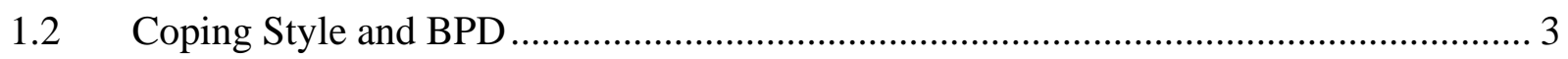

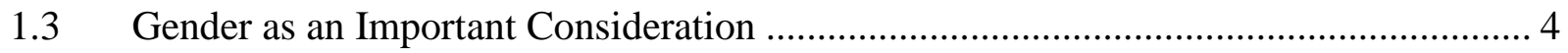

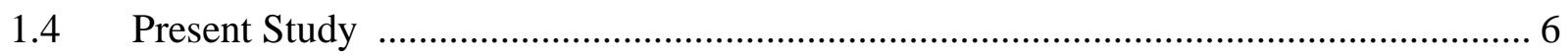

Chapter 2: Measures.................................................................................................................................

$2.1 \quad$ Participants and Procedures …………………....................................................... 7

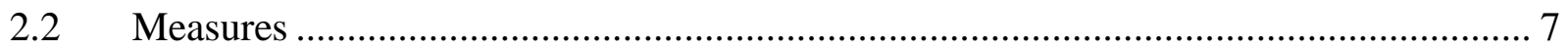

2.2.1 Wisconsin Personality Disorders Inventory ............................................................. 7

2.2.2 Coping Inventory for Stressful Situations........................................................... 7

2.2.3 Social Adjustment Scale - Self Report.................................................................. 8

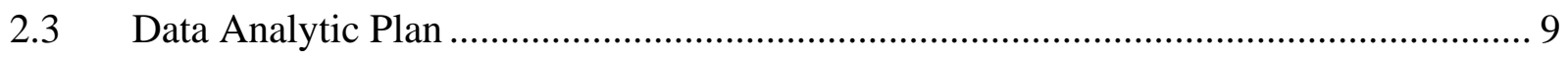

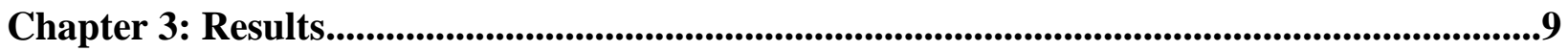




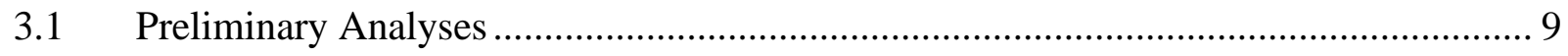

3.2 Moderated-Mediation Model .............................................................................. 9

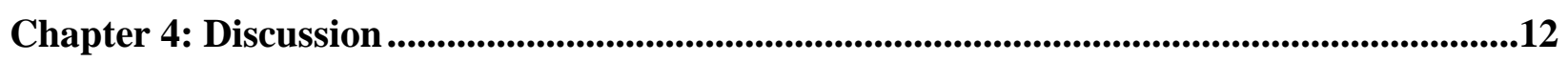

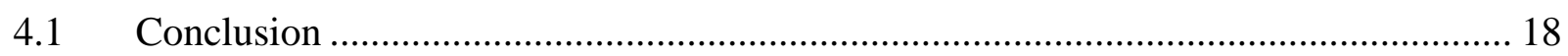

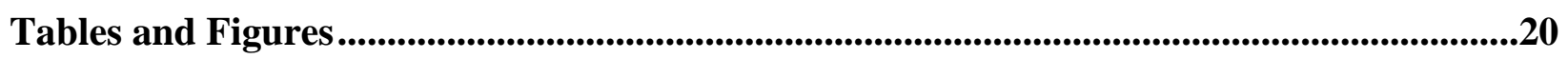

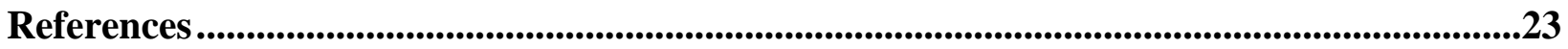




\section{List of Tables}

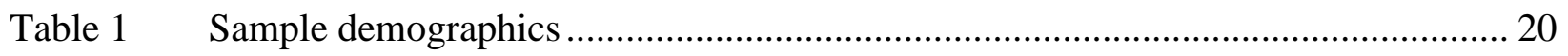

Table 2 Pearson correlation coefficients and descriptive statistics for primary variables ..... 20

Table 3 Multiple mediation model examining associations between BPD (IV) and social role

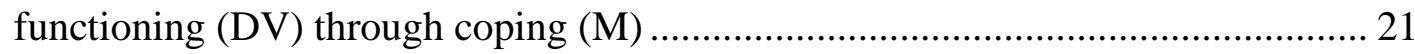

Table 4 Conditional indirect effects through BPD symptoms on social role functioning

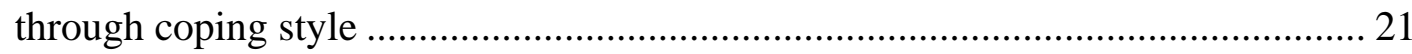




\section{List of Figures}

Figure 1 Moderated multiple mediation model for coping styles mediating the association of borderline personality disorder symptoms and difficulties in social role functioning 


\section{List of Abbreviations}

BPD: Borderline personality disorder

CI: Confidence interval 


\section{Acknowledgements}

I extend my fullest gratitude to the faculty, staff and my cohort at UBC, who continually keep me inspired and passionate about our field. I owe particular thanks to Dr. Thomas Motl, Dr. Rhea Owens, Dr. Michele Bowers, and Dr. Marla Buchanan for their guidance and insight.

I would like to thank Dr. Daniel Cox for his compassion, patience, and sense of humour. I feel extremely fortunate to have had him as my supervisor, and am so grateful for his support and confidence in me throughout this part of my academic career. Thanks as well to Dr. Kealy and Dr. Chapman for their invaluable insights, feedback, and presence on my committee.

Special thanks are owed to my partner Tim for his unwavering support and steadfastness. And to my sweet Cecilia Bean, thank you for your smile and your unending curiosity. I hope I've made you both proud. 


\section{Chapter 1: Introduction}

Borderline personality disorder (BPD) is characterized by instability of interpersonal relationships, self-identity, and emotions, causing significant distress amongst those affected and substantial impairment in daily life functioning. (DSM-5; American Psychiatric Association, 2013; Zielinski \& Veilleux, 2014). Additionally, men and women have been found to have noted differences in symptom presentation of BPD, despite similar levels of symptom severity experienced across genders (Skodol \& Bender, 2003). Some of the most severe problems among individuals with BPD that require intervention (self-injury, suicide attempts, and/or impulsive/reckless behaviours) often stem from social difficulties or dysfunction and occur across a wide variety of domains (Dixon-Gordon et al., 2011). Therefore, a more nuanced understanding of the social difficulties individuals with BPD experience is needed, and further investigation may inform continued efforts to ameliorate long-term suffering and dysfunction.

\subsection{Social Role Functioning in BPD}

Individuals diagnosed with BPD often show marked instability in social relationships, which may be coupled with maladaptive or non-normative social behaviours directed at the self and others (DSM-5; American Psychiatric Association, 2013). Individuals diagnosed with BPD can fluctuate through extreme idealization and devaluation towards others, and often exhibit intense fear of abandonment. Additionally, displays of anger or hostile behaviour can serve to further detriment social functioning, leading to fewer positive relationships, increased relationship termination, and smaller, more discordant social networks (Clifton, Pilkonis, \& McCarty, 2007). The presence of high BPD features has been associated with social interactions that may be perceived as overly assertive and devoid of intimacy, or submissive and lacking in confidence (Ryan \& Shean, 2007). Moreover, individuals with BPD often exhibit poor social 
problem-solving skills (Bray, Barrowclough \& Lobban, 2007), which are often critical to the overall development and maintenance of BPD (Kosson, Walsh, Rosenthal, \& Lynch, 2015), though the etiology of these interpersonal disruptions is debated. A few factors, including difficulties interpreting social cues (Schaffer, Barak, \& Rassovsky, 2015), deficits in emotion regulation skills (Dixon-Gordon, Chapman, Lovasz, \& Walters, 2011), enhanced perception of social stimuli that is often attached to negative, self-referential emotional states (Dinsdale \& Crespi, 2013) and strong reaction to perceived rejection or social abandonment (Romero-Canyas, Downey, Berenson, Ayduk, \& Kang, 2010), likely interplay to form complex, pervasive patterns of social dysfunction. Research also suggests when individuals with BPD generate solutions to social problems, these solutions are often passive and indirect, or impulsive and careless thereby insufficient to remedy the social problem at hand (Stepp et al., 2011). Collectively, these deficits of social communication and interaction have been found to be pervasive over time and are the most resistant to treatment intervention, enduring after other BPD related difficulties have abated (Stepp, Hallquist, Morse, \& Pilkonis, 2011).

Social role functioning, more specifically, refers to the capacity of an individual to act in age and socially appropriate ways in specific contexts, informed by social norms and preconceived ideas of situationally appropriate behaviour (Sherborne, Stewart, \& Wells, 1992). Deficits in social role functioning have been linked to BPD (Narud, Mykletun, \& Dahl, 2005). For example, difficulty forming and maintaining stable, secure, and healthy relationships is a defining characteristic of BPD. Social relationships among individuals with BPD are often characterized by intense periods of volatility, fluctuating between extreme idealization and devaluation ((DSM-5; American Psychiatric Association, 2013). Additionally, individuals with BPD often report relationship insecurity (Berenson, Johnson, Zhao, Nynaes, \& Goren, 2018), 
centered around fears of abandonment followed by frantic efforts to avoid the perceived abandonment. As such, it is not surprising that individuals with BPD are more likely to be separated or divorced, and to have reoccurring interpersonal difficulties with romantic partners, bosses, friends, neighbours, and family than individuals without a BPD diagnosis (Javaras, Zanarini, Hudson, Greenfield, \& Gunderson, 2017). Additionally, any of these relationships that are maintained tend to be of lower quality (shallow, superficial, and/or tumultuous).

Social role dysfunction has also been associated with BPD in employment settings. Embodying the social role of employee poses unique challenges, as maintaining and succeeding in the workplace is often dependent on task performance (Thompson, Payne, Horner, \& Morey, 2012). Individuals with BPD are likely to struggle with planning and implementing effective strategies to complete tasks, as emotion dysregulation may derail focus, thereby impacting overall job performance (Thompson et al., 2012). These deficits may be more pronounced if the work involves repeated social interaction or interdependence on coworkers. Indeed, research suggests that individuals with BPD are less likely to have post-secondary education, less likely to sustain employment, and more likely to be on disability (Zanarini, Frankenburg, Hennen, Reich, $\&$ Silk, 2005). These outcomes have also been found to be coupled with low work satisfaction, unrealistically high expectations of perfection, avoidance of tasks and procrastination, and generally poor work habits (Salz, 1983). Overall, individuals with BPD often report less social support, more conflicts, and less integration across multiple social domains (Beeney, Hallquist, Clifton, Lazarus, \& Pilkonis, 2018).

\subsection{Coping Style and BPD}

Coping is a set of overt and covert strategies employed to deal with stressful situations, and manage the emotional consequences (Pereira-Morales, Adan, Lopez-Leon, \& Forero, 2018). 
Coping styles have been conceptualized as distinct strategies that people use when faced with stressors: task-oriented coping (direct problem solving), emotion-oriented coping (rumination, increased negative affect, self-blame, and emotional displays like crying), and avoidanceoriented coping (minimizing, denying, or circumventing stressful situations; Endler \& Parker, 1990). Avoidance-oriented coping can be further subdivided into distraction (solo) and social diversion (with others; Pereira-Morales et al., 2018).

While the range of coping strategies employed by healthy adults tends to be large, difficulties associated with BPD often limit the repertoire of coping strategies, denoting high levels of coping inflexibility, which can produce unproductive or inefficient coping mechanisms (Linehan, Bohus, \& Lynch, 2007). Emotion-oriented coping is most often used by individuals with BPD in stressful situations, resulting in marked increases in irritability, oppositionality, negative affect, impulsivity, and aggression (Dougherty, Bjork, Huckabee, Moeller, \& Swann, 1999). Conversely, low rates of task-oriented coping are often found amongst individuals with BPD (Kremers, Spinhoven, Van der Does, \& Van der Dyck, 2006). Additionally, avoidanceoriented coping is often found in individuals with BPD, with this form of coping thought to be associated with experiential avoidance: behaviour that functions to avoid or escape from unwanted experiences (Hayes, Wilson, Gifford, Follette, \& Strosahl, 1996). This phenomenon may include suppressing emotional experience or expression, avoiding situations associated with distress, and engaging in both adaptive and maladaptive distraction behaviours (Hayes et al., 1996).

\subsection{Gender as an Important Consideration}

Notable gender differences have been observed regarding BPD diagnosis and its presentation. Women are more often diagnosed with BPD (Skodol \& Bender, 2003), and women 
with BPD have also been found to have a higher prevalence of diagnostic symptoms, as well as increased symptom severity compared to men (Silberschmidt, Lee, Zanarini, \& Schulz, 2015). Further, women with BPD show a more internalizing clinical presentation than men, with higher rates of anxiety, depression, and PTSD symptoms (Skodol \& Bender, 2003). Conversely, men present with more externalizing symptoms, with increased presence of substance use and impulsive behaviours. Women with BPD displayed more aggression and hostility towards others, which likely detriments functioning in social relationships (Skodol \& Bender, 2003), counter to expected results due to the social desirability of women and girls towards less aggressive behaviours.

These differences have potential implications on the relationship between coping styles and social functioning in individuals with BPD. Gender affects each aspect of the social process, particularly when considering behaviour in stressful situations (Matud, 2004). Gender determines both whether a situation will be perceived as stressful, and then influences coping responses and the social implications of those stress reactions. One main hypothesis for this difference focuses on the traditional socialization patterns of men and women. These patterns in women tend to prescribe coping that is more emotionally laden and socially oriented, whereas the socialization patterns of men tend to promote emotional avoidance and goal-focused coping styles (Almeida \& Kessler, 1998). Though multiple studies have found results consistent with this hypothesis (Endler \& Parker, 1990, Ptacek, Smith, \& Dodge, 1994), some evidence suggests that gender differences in the use of coping strategies may be diminishing and are becoming less constrained by gender, paralleling social shifts in gender roles (Matud, 2004). Within a BPD population, however, it is unclear whether these gender differences in coping with stress are present, and whether they follow trends associated with non-clinical populations. 


\subsection{Present Study}

Maladaptive coping and social dysfunction are hallmarks of BPD. Further, there is strong evidence that there are gender differences in the coping styles and interpersonal behaviors associated with BPD. Men with presence of high BPD symptoms have been thought to present with externalizing symptoms and emotional avoidance when faced with stress, whereas women with high BPD symptoms are thought to present with internalizing symptoms; both of which likely result in social dysfunction amongst those affected. However, it is unclear specifically how gender influences these associations. Therefore, the purpose of this study was twofold; to examine the mediating (i.e., indirect) effects of coping styles on the association between BPD symptoms and social dysfunction and to examine if gender moderated the mediating effects. 


\section{Chapter 2: Methods}

\subsection{Participants and Procedures}

Participants $(N=233)$ were consecutively admitted patients in a psychiatric daytreatment program for personality disorder or significant personality dysfunction. Participants completed pre-screening assessments prior to beginning the program. Affiliated research ethics boards approved this study and all participants provided informed consent. Demographic characteristics are presented in Table 1.

\subsection{Measures}

\subsubsection{Wisconsin Personality Disorders Inventory - IV. (WISPI-IV; Klein et al., 1993).}

The Wisconsin Personality Disorders Inventory - IV is a 214-item self-report of DSM-IV personality disorder symptoms. The WISPI-IV includes scales for each of the eleven personality disorders (only the BPD scale was used in analysis, but all eleven were administered). Items are rated on a 10-point scale from 1 (never/not at all) to 10 (always/extremely). The WISPI-IV has been shown to have high internal consistency with alphas averaging .88 across all scales (Barber \& Morse, 1994). Additionally, the WISPI-IV has shown convergent and discriminant validity amongst individuals diagnosed BPD (Klein et al., 1993; Smith, Klein, \& Benjamin, 2003). The WISPI-IV also shows high concurrent validity with other personality disorder scales, such as the Personality Diagnostic Questionnaire (Hyler et al., 1994) and the Millon Clinical Multiaxial Inventory - I (Millon, 1983). In this study, we used the mean borderline symptom score, with higher scores indicating greater BPD symptom severity.

\subsubsection{Coping Inventory for Stressful Situations. (CISS; Endler \& Parker, 1990).}

The CISS is a 48-item self-report scale that measures three dispositional coping strategy styles: task-oriented coping, emotion-oriented coping, and avoidance-oriented coping. 
Avoidance-oriented coping is further sub-divided into two specific avoidance strategies:

distraction and social diversion. Presently, we used all four subscales. The items are rated on a 5point scale from 1 (not at all) to 5 (very much) and participants indicate how frequently they engage in various coping activities during a stressful event. Subscale scores were the sum of item responses, with higher scores indicating greater use of that coping style. The CISS has been found to have stable factor structure, test-retest reliability, internal validity and construct validity (Cosway, Endler, Sadler, \& Deary., 2000; Endler \& Parker, 1990).

2.2.3 Social Adjustment Scale - Self-Report. (SAS-SR; Weissman, 1999).

The SAS-SR is a 42-item self-report scale derived from the Social Adjustment Scale Interview (Weissman \& Bothwell, 1976) that assesses role performance in the past two-weeks across seven role domains: work/school, social/leisure, economic, extended family, primary relationship, parental, and the family unit. Participants rated their impairment in each domain from 1 (not at all) to 5 (very much). We created a global adjustment score by computing the mean of item responses, with higher scores indicating greater overall social role dysfunction. Previous research using the SAS-SR shows test-retest reliability and construct validity (Delvecchio, Di Riso, Lis, \& Salcuni, 2016).

\subsection{Data Analytic Plan}

Primary analyses were conducted using moderated mediation via the PROCESS macro in SPSS version 25 (Hayes, 2013). This allowed us to simultaneously examine (a) the mediating (i.e., indirect) effects of coping styles between the association of BPD symptoms and social role dysfunction, and (b) gender's moderating effects on the mediating effects of coping styles. To facilitate a normally distributed indirect effect, we bootstrapped each of the indirect effect's 
sampling distributions 20,000 times. Indirect effects were considered significant if the $95 \%$ confidence intervals (CIs) did not straddle zero.

Power analyses conducted via G*Power (Erdfelder, Faul, \& Buchner, 1996) found that number of women in the sample $(N=160)$ was sufficient to detect effect sizes of $d=0.2$, while the number of men in the sample $(N=78)$ was sufficient to detect effect sizes of $d=0.8$. 


\section{Chapter 3: Results}

\subsection{Preliminary Analyses}

All continuous variables fell within acceptable ranges of normality as noted by ShapiroWilks tests $(p>0.05)$, and scatterplots revealed no multivariate outliers. Means, standard deviations, and correlations of all primary study variables are shown in Table 2.

\subsection{Moderated-Mediation Model}

First, we determined whether each mediating effect should be examined separately for women and men by evaluating the index of moderated mediation. A significant index of moderated mediation indicates that the mediating effects are different for men and women; therefore, when significant, mediating effects should be evaluated separately. Results indicated that gender moderated the mediating effects of emotion-oriented coping $(b=.04, S E=.02,95 \%$ CI $[.003, .09])$ and social diversion-oriented coping $(b=.03, S E=.02,95 \% \mathrm{CI}[.01, .07])$, but did not moderate the mediating effects of task $(b=.01, S E=.02,95 \% \mathrm{CI}[-.02, .04])$ or distraction oriented coping $(b=.00, S E=.01,95 \% \mathrm{CI}[-.03, .02])$.

Because the index of moderated mediation was not significant for task or distractionoriented coping, we examined the unconditional mediating effects for these constructs. Results indicated that neither task or distraction-oriented coping significantly mediated the association between BPD symptoms and social maladjustment (see Table 2).

Because the index of moderated mediation was significant for emotion and distractionoriented coping, we examined the conditional mediating effects (i.e., the mediating effects for men and the mediating effects for women). Results indicated that - for women, but not for men (a) emotion-oriented coping significantly mediated the association between BPD symptoms and social role functioning $(b=.08,95 \% \mathrm{CI}[.01, .06])$, and (b) social diversion-oriented coping 
significantly mediated the associated between BPD symptoms and social role functioning $(b=$ $.01,95 \%$ CI $[.01, .04]$. 


\section{Chapter 4: Discussion}

The present study extended our understanding of gender's influence on the association between BPD symptoms and social maladjustment through coping. Our primary finding was that emotion and distraction-oriented coping mediated the association between BPD and social maladjustment for women, but not for men. Also, that for men and women, neither task or distraction-oriented coping significantly mediated the association between BPD symptoms and social maladjustment.

While direct associations between BPD symptoms and coping styles were congruent with previous literature, more interesting to the scope of this study are the overall mediating effects of these coping styles and their relationship to social functioning, particularly with the inclusion of gender as a moderator of these indirect effects. Emotion-oriented coping was found to mediate the relationship between BPD symptoms and social role functioning in women, echoing previous literature about emotion dysregulation and emotion-oriented coping. As BPD symptoms increased among women, emotion-oriented coping also increased, which in turn was related to an increase in social role dysfunction, encompassing difficulties performing in norm-informed, socially sanctioned ways in roles such as employee or partner (Spitzer, Fischbacher, Herrnberger, Grön, \& Fehr, 2007). Emotion-oriented coping, encompassing coping strategies including increased negative affect, rumination, and crying (McWilliams, Cox, \& Enns, 2003), may not likely be universally useful in promoting social role functioning. Crying or extreme anger presentation, for example, may engender aversive reactions from others, contributing to tension in team/group settings and interfere with task performance in the workplace, where taskoriented coping is likely expected (Thompson et al., 2012). Simple tasks may become overwhelming or marred with difficulty, impacting social standing and acting in opposition to 
expected behaviour. This finding adds to literature regarding the detriment of emotion dysregulation in individuals with BPD symptoms, and its inherent interrelatedness to coping. While task-oriented coping strategies may be the most adaptive in times of stress, they are often not salient or available (McWilliams, Cox, \& Enns, 2003), so emotion-oriented coping may be utilized to provide a sense of emotional release or outlet on a short-term basis. However, it often fails to alleviate long-term stress or promote necessary change, decreasing overall quality of life (Pereira-Morales et al., 2018). These results align with current understanding of how women with BPD are often found to present with more internalizing symptoms of emotion dysregulation, and may perhaps also lend to some speculation about how women with BPD use emotion-oriented coping in social contexts. Often, some degree of emotion-oriented coping can be adaptive, ideally met with empathic responses from others and utilized to effect problem resolution. Indeed, women may be socialized to have greater access to these responses (Hobfoll, 2014). From this, it may be the case that women with BPD have not received the same level of empathic responsiveness from formative social relationships, and have thus developed an exaggerated form of emotional coping that reflects desperate efforts to be responded to by those around them, despite ultimately leading to the opposite result. Additionally, this pattern of emotion-oriented coping in women with BPD may reflect an activation of an internal image of helplessness in the face of adversity, and the belief that one must appeal for a rescuer to solve their problems.

Additionally, social diversion-oriented coping showed an interesting pattern of association in women. As severity of BPD symptoms increased, social diversion-oriented coping decreased, which was subsequently associated with an increase of social role dysfunction. This seems to contradict previous research regarding avoidance-oriented coping, which includes 
coping strategies such as denial of the problem or resulting distress, disengagement, and social withdrawal (Pereira-Morales et al., 2018; Gardner, Archer, \& Jackson, 2012) and their presence in BPD populations. Though avoidance-oriented coping has been found to be heightened in clinical presentations of BPD (Gratz, Rosenthal, Tull, Lejuez, \& Gunderson, 2009), specifically investigating social diversion-oriented coping may shed more light on how individuals with BPD access and utilize social support when faced with stress, and how this coping style impacts selfregulation processes.

When utilizing social diversion-oriented coping, the individual is using social situations and interaction to detach from and avoid the problem or situationally stressful task. The individual may seek social connection as a means of seeking emotional support, which has been posited to allow for stress buffering, reducing or eliminating the effects of stressful experiences by the social network offering less threatening interpretations of adverse events, as well as utilization of the social network to distance or distract oneself from the stressor (Cohen, 2004). Social diversion, thus, represents stressor avoidance in conjunction with positive emotional coping (Endler \& Parker, 1999). Research has shown that social diversion-oriented coping is associated with life satisfaction and increased positive affect (Saklofske, Austin, Mastoras, Beaton, \& Osbourne 2012), as well as increased perceived social support (Ponizovsky, Grinshpoon, Sasson, \& Levav, 2004). More generally, social support, defined by Cohen (2004) as instrumental, informational, and emotional support from others intended to help an individual cope with stress, is a protective factor for psychological well-being, and stable, satisfying relationships can serve to shield individuals with BPD from distress (Rosenbach \& Renneberg, 2014). Interestingly, presence of high BPD symptoms has been found to be predictive of more perceived social support and more social network partners overall (Lazarus, Southward, \& 
Cheavens, 2016). So, it could be expected that we would see positive associations between BPD and social diversion-oriented coping, and a subsequent decrease in social role dysfunction. However, when considering the findings of this study, where the opposite occurred, the question arises: what would prevent women with BPD from seeking social engagement and support if it is part of a seemingly adaptive coping style that may help improve overall social functioning and feelings of positive affect?

Recent research has sought to explore this question by examining underlying cognitive processes of individuals with BPD in social contexts, revealing a double-edged sword of social support seeking in BPD. While individuals with BPD may predict a greater number of social partners, it is the composition and quality of these social networks that is insufficient (Lazarus, Southward, \& Cheavens, 2016). Individuals with BPD tend to seek novel partnerships, which may prevent investment in more familiar and adaptive partnerships. Additionally, these social partners are perceived as less supportive and reliable, and networks often contain emotionally intense partners and those with whom relationships have been previously severed (Zielinski \& Veilleux, 2014; Clifton, Pilkonis, \& McCarty, 2007). These factors combine for a poor-quality social network that is often unable to support the individual when they seek it. Furthermore, BPD specific deficits may impact the receiving of social support when it is available, particularly expectations and rejection and reduced trusting behaviour (Lazarus, Southward, \& Cheavens, 2016). This rejection sensitivity can alter perception of social interactions, with individuals with BPD reporting an increased sense of exclusion and a tendency to feel excluded even when objectively included (Renneberg, Herm, Hahn, Staebler, Lammers, \& Roepke, 2012). Together, these two facets would likely highly detriment social integration and role functioning, especially in states of distress, prompting states of emotional invalidation and self-fulfilling prophecies of 
social rejection in individuals with BPD (Zielinski \& Veilleux, 2018). Particularly amongst women with high BPD symptoms, whom are often expected and socialized to be more sociallyengaged than men, these difficulties may prevent the usage of social diversion-oriented coping despite the desire to interact socially. The potential myriad of pitfalls they may encounter trying to engage may dissuade social diversion, even if they see its potential utility. Women with BPD who use social diversion-oriented coping may do so initially with the intention of engaging in social support seeking, but may believe that these others cannot offer the resources necessary to bolster the self in such a manner that will ultimately help resolve difficulties. These issues may only have been seen in women within this sample due to the way women access support during times of stress. Hobfoll (2014) extensively discussed social support seeking as a primary coping mechanism for women when faced with stress, which may serve as a prototype for social diversion-oriented coping for women with BPD. So, in this sample of women with severe personality dysfunction, deficits are likely to become more salient. A lack of results among men may be due in part to the smaller number of male participants within the study, with power analysis showing only the ability to detect large effect size among men. Additionally, further avenues for research including men with BPD may include examining patterns of BPD symptomology amongst male participants including severity and symptom presentation, to make more direct theoretical links to coping and social role dysfunction.

These interactions between BPD symptoms, coping and social dysfunction have important implications for clinical practice. Firstly, increased dysfunction across various social roles that emerges from problematic coping might engender further emotional distress by confirming dysphoria and maladaptive cognitive-affective schema that individuals with BPD have about themselves and the world around them. Specifically targeting and seeking to modify 
coping strategies through therapy may work towards breaking this cycle. In turn, this may give individuals with BPD a sense of increased social efficacy, thereby potentially reducing dysphoria and altering underlying schemas or internal models of social interaction and functioning. Additionally, therapy specifically targeting coping can work to help develop the individual's capacity for handling emotions without having to rely on ineffective or maladaptive coping strategies, which may decrease coping inflexibility. Thus, specifically targeting and heightening the ability to manage these emotions through a broader, more suitable application of coping strategies that are situation-appropriate and socially nuanced might allow for the ongoing inclusion of coping strategies that may have been previously inaccessible.

Additionally, therapy can be utilized as an effective social role modelling experience, in which the therapist models appropriate role functioning and adaptive coping in session. As the social difficulties in BPD tend to outlast other deficits (Stepp, Hallquist, Morse, \& Pilkonis, 2011), dealing with the distress that could arise while learning more adaptive forms of coping in a safe environment, without consequences such as a relationship ending or getting fired from their place of employment, could be a particularly useful skill for individuals with BPD. The therapist must also identify what current coping strategies are already in place, especially those that are utilized in social situations, and evaluate the client's capacity for change so that they may specifically tailor interventions to target areas of deficit.

This study has a few notable limitations. First, the results of the current study should be interpreted considering methodological limitations around the use of cross-sectional, selfreported data. Analyses and inference relied solely on self-report data from pre-screening questionnaires of a larger study, and as such must be interpreted preliminarily. Although theory supports the proposed moderated mediation model, the cross-sectional nature of this data and 
design cannot imply causality (Gardner, Archer, \& Jackson, 2012). Future research should focus on multimethod reporting of all variables, particularly coping and social role functioning, to provide a more nuanced understanding of coping social contexts in the presence of severe personality dysfunction. Observer ratings for assessing coping have higher external validity than self-report (Gardner, Archer, \& Jackson, 2012). Additionally, observing coping and social role functioning in vivo over multiple time points may provide better understanding of the dynamic nature of social interaction which simply cannot be assessed by a single self-report (Kramer, 2012). This could be accomplished through observer ratings, or ecological momentary assessment methods. Further, this study only included age as a covariate in the examined models and did not control for the influence of Axis I and other Axis II disorders. As this study was an early foray into the relationship between BPD symptoms, coping and social role functioning, this may be a particularly important avenue to pursue in future research, given the high comorbidity of diagnoses and level of detriment experienced.

\subsection{Conclusion}

Our findings highlight the importance of the relationship between coping and social functioning in BPD populations. Findings suggest that social diversion-oriented coping may be important to improving multiple facets of functioning in individuals with BPD. Given the pervasive nature of social deficits in BPD, and the increased social isolation often experienced by those with a diagnosis, future research should investigate this relationship by incorporating assessment of social support and social network composition. This may further inform psychological treatment for individuals with BPD, prioritizing social functioning in tandem to managing emotion regulation difficulties. Targeting these avenues early and simultaneously may 
not only improve client adherence to both treatment protocols and recommendations but may impactfully improve quality of life for individuals with BPD. 


\section{Tables and Figures}

Table 1. Sample Demographics $(N=233)$

\begin{tabular}{lc}
\hline & Mean (SD) or $n(\%)$ \\
\hline Age (years) & $37.32(11.00)$ \\
Gender & \\
Male & $73(31.3 \%)$ \\
Female & $160(68.7 \%)$ \\
Racial Origin & \\
Caucasian & $210(90.2 \%)$ \\
First Nations & $4(1.8 \%)$ \\
Other & $19(8.0 \%)$ \\
Marital Status & \\
Single & $71(30.4 \%)$ \\
Married & $59(25.6 \%)$ \\
Separated & $16(6.9 \%)$ \\
Divorced & $27(11.9 \%)$ \\
Widowed & $4(1.5 \%)$ \\
Other & $56(24.0 \%)$ \\
Education Level & \\
Did not complete high school & $43(18.4 \%)$ \\
High school completed & $54(23.2 \%)$ \\
Some post-secondary & $82(35.4 \%)$ \\
Post-secondary completed & $90(38.6 \%)$ \\
Previous Psychiatric Treatment & $163(70.3 \%)$ \\
Previous Psychiatric Hospitalization & $72(31.2 \%)$ \\
Current Axis I Diagnosis & $222(95.3 \%)$ \\
Current Axis II Diagnosis & $164(70.7 \%)$ \\
Currently on Psychotropic Medication & $200(86.2 \%)$ \\
\hline
\end{tabular}

Table 2. Pearson correlation coefficients and descriptive statistics for primary variables

\begin{tabular}{lcccccccccc}
\hline & 1 & 2 & 3 & 4 & 5 & 6 & Mean & SD & Skew & Kurtosis \\
\hline 1. WISPI-IV Borderline & - & & & & & & 3.76 & 1.46 & 0.80 & 0.94 \\
symptom severity & $-.25^{* *}$ & - & & & & & 46.42 & 12.16 & 0.10 & -0.33 \\
2. CISS - Task Scale & $.44^{* *}$ & $-.40^{* *}$ & - & & & & 55.50 & 10.47 & -0.58 & 0.31 \\
3. CISS - Emotion Scale & $.23^{* *}$ & $-.14^{*}$ & $.33^{* *}$ & - & & & 22.56 & 6.16 & 0.09 & -0.29 \\
4. CISS - Distraction & -.07 & $.35^{* *}$ & -.01 & $.17^{* *}$ & - & & 13.64 & 4.63 & 0.23 & -0.52 \\
5. CISS - Social Diversion & $.38^{* *}$ & $-.25^{* *}$ & $.24^{* *}$ & $.14^{*}$ & $-.27^{* *}$ & - & 2.52 & 0.51 & 0.63 & 0.79 \\
6. SAS-SR: Social Adjustment
\end{tabular}

WISPI-IV: Wisconsin Personality Disorders Inventory; CISS: Coping Inventory for Stressful Situations; SAS-SR: Social Adjustment Scale - Self Report. *p $<.05, * * p<.01, * * * p<.001$. 
Table 3. Multiple mediation model examining associations between BPD (IV) and social role functioning (DV) through coping $(\mathrm{M})$.

\begin{tabular}{|c|c|c|c|c|c|c|}
\hline Mediator (M) & $\begin{array}{l}\text { Effect of IV } \\
\text { on M (a) }\end{array}$ & $\begin{array}{c}\text { Effect of M } \\
\text { on DV (b) }\end{array}$ & $\begin{array}{l}\text { Direct Effect } \\
\left(c^{\prime}\right)\end{array}$ & $\begin{array}{c}\text { Indirect } \\
\text { Effect (a x b) }\end{array}$ & $\begin{array}{c}\text { Indirect } \\
\text { effect (95\% } \\
\text { CI) }\end{array}$ & $\begin{array}{c}\text { Total Effect } \\
\text { (c) }\end{array}$ \\
\hline Total effect & & & $.079 * * *$ & .104 & & $.183^{* *}$ \\
\hline $\begin{array}{l}\text { Task- } \\
\text { oriented } \\
\text { coping }\end{array}$ & $-1.256^{*}$ & -.004 & & .005 & {$[-.016, .019]$} & \\
\hline $\begin{array}{l}\text { Emotion- } \\
\text { oriented } \\
\text { copingt }\end{array}$ & $2.898 * * *$ & $.029 * *$ & & .084 & {$[.007, .056]$} & \\
\hline $\begin{array}{l}\text { Distraction- } \\
\text { oriented } \\
\text { coping } \\
\text { Social }\end{array}$ & $.761^{*}$ & .005 & & .003 & {$[-.006, .014]$} & \\
\hline $\begin{array}{l}\text { Diversion- } \\
\text { oriented } \\
\text { coping }{ }^{\dagger}\end{array}$ & $-.375^{*}$ & $-.032 * * *$ & & .012 & {$[.005, .042]$} & \\
\hline
\end{tabular}

Note: IV = BPD symptoms; bolded confidence intervals do not include a zero, indicating a significant indirect effect. $†$ Mediators are significantly moderated by gender. ${ }^{*} p<.05,{ }^{* *} p<.01,{ }^{* * *} p<.001$

Table 4. Conditional indirect effects of BPD symptoms on social role functioning through coping style.

\begin{tabular}{lc}
\hline Coping style & Indirect effect $(95 \% \mathrm{CI})$ \\
\hline Task & $.0041(-.016, .019)$ \\
Women & $-.0073(-.038, .018)$ \\
Men & $\mathbf{. 0 3 0}(.007, .056)$ \\
Emotion & $-.014(-.057, .019)$ \\
Women & \\
Men & $.0029(-.006, .014)$ \\
Distraction & $.0033(-.010, .030)$ \\
Women & \\
Men & $\mathbf{. 0 2 0 7}(\mathbf{. 0 0 5}, \mathbf{. 0 4 2})$ \\
Social Diversion & $-.0083(-.050, .026)$ \\
$\quad$ Women & \\
Men &
\end{tabular}




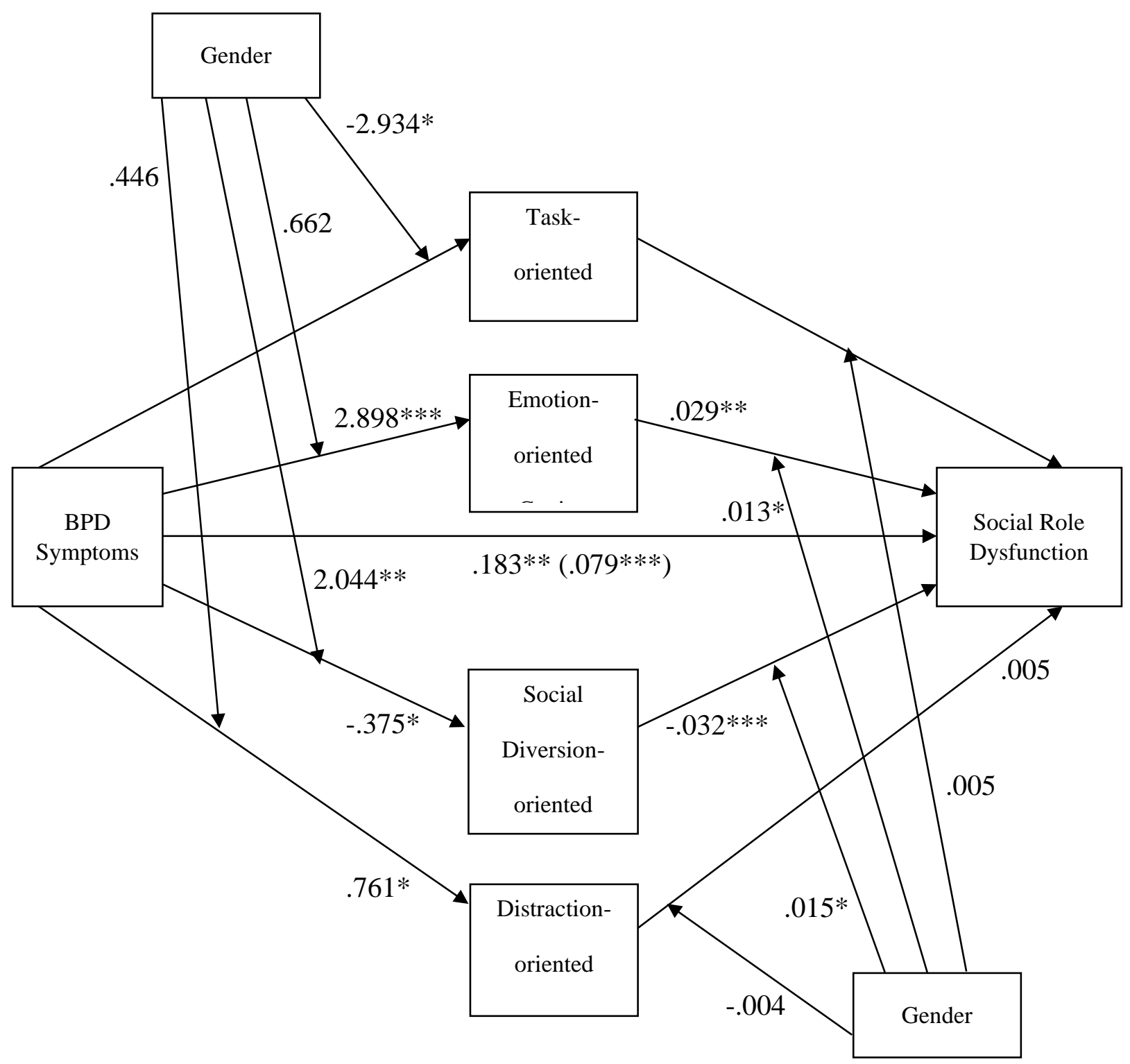

Figure 1. Moderated multiple mediation model for coping styles mediating the association of borderline personality disorder symptoms and difficulties in social role functioning. ${ }^{*} p<.05$, $* * p<.01, * * * p<.001$. 


\section{References}

Almeida, D. M., \& Kessler, R. C. (1998). Everyday stressors and gender differences in daily distress. Journal of personality and social psychology, 75(3), 670. doi:10.1037/00223514.75.3.670

Barber, J. P., \& Morse, J. Q. (1994). Validation of the Wisconsin Personality Disorders Inventory with the SCID-II and PDE. Journal of Personality Disorders, 8(4), 307-319. doi:10.1521/pedi.1994.8.4.307

Beeney, J. E., Hallquist, M. N., Clifton, A. D., Lazarus, S. A., \& Pilkonis, P. A. (2018). Social disadvantage and borderline personality disorder: A study of social networks. Personality Disorders: Theory, Research, and Treatment, 9(1), 62. doi:10.1037/per0000234

Berenson, K. R., Johnson, J. C., Zhao, F., Nynaes, O., \& Goren, T. (2018). Borderline personality features and integration of positive and negative thoughts about significant others. Personality Disorders: Theory, Research, and Treatment, 9(5), 447-457. doi:10.1037/per0000279

Bray, S., Barrowclough, C., \& Lobban, F. (2007). The social problem-solving abilities of people with borderline personality disorder. Behaviour Research and Therapy, 45(6), 14091417. doi:10.1016/j.brat.2006.06.011

Chapman, A. L., Dixon-Gordon, K. L., \& Walters, K. N. (2011). Experiential avoidance and emotion regulation in borderline personality disorder. Journal of Rational-Emotive \& Cognitive-Behavior Therapy, 29(1), 35-52. doi:10.1007/s10942-011-0124-6

Chun, S., Harris, A., Carrion, M., Rojas, E., Stark, S., Lejuez, C., ... \& Bornovalova, M. A. (2017). A psychometric investigation of gender differences and common processes across 
borderline and antisocial personality disorders. Journal of abnormal psychology, 126(1), 76-88. doi:10.1037/abn0000220

Clifton, A., Pilkonis, P. A., \& McCarty, C. (2007). Social networks in borderline personality disorder. Journal of Personality Disorders, 21(4), 434-441.

doi:10.1521/pedi.2007.21.4.434

Cohen, S. (2004). Social relationships and health. American psychologist, 59(8), 676. doi:10.1037/0003-066x.59.8.676

Cosway, R., Endler, N. S., Sadler, A. J., \& Deary, I. J. (2000). The Coping Inventory for Stressful Situations: Factorial Structure and Associations With Personality Traits and Psychological Health. Journal of applied biobehavioral research, 5(2), 121-143. doi:10.1111/j.1751-9861.2000.tb00069.x

Delvecchio, E., Di Riso, D., Lis, A., \& Salcuni, S. (2016). Adult attachment, social adjustment, and well-being in drug-addicted inpatients. Psychological reports, 118(2), 587-607. doi:10.1177/0033294116639181

Dinsdale, N., \& Crespi, B. J. (2013). The Borderline Empathy Paradox: Evidence and Conceptual Models for Empathic Enhancements in Borderline Personality Disorder. Journal of Personality Disorders, 27(2), 172-195. doi:10.1521/pedi.2013.27.2.172

Dixon-Gordon, K. L., Chapman, A. L., Lovasz, N., \& Walters, K. (2011). Too upset to think: The interplay of borderline personality features, negative emotions, and social problem solving in the laboratory. Personality Disorders: Theory, Research, and Treatment, 2(4), 243. doi:10.1037/a0021799 
Dougherty, D. M., Bjork, J. M., Huckabee, H. C., Moeller, F. G., \& Swann, A. C. (1999).

Laboratory measures of aggression and impulsivity in women with borderline personality disorder. Psychiatry research, 85(3), 315-326. doi:10.1016/s0165-1781(99)00011-6

DSM-5 American Psychiatric Association. (2013). Diagnostic and statistical manual of mental disorders. Arlington: American Psychiatric Publishing.

Endler, N. S., \& Parker, J. D. (1990). Multidimensional assessment of coping: A critical evaluation. Journal of personality and social psychology, 58(5), 844-854. doi:10.1037/0022-3514.58.5.844

Endler, N. S., \& Parker, J. D. (1999). Coping Inventory for Stressful Situations (CISS) Manual. Toronto: Multi-Health System.

Erdfelder, E., Faul, F., \& Buchner, A. (1996). GPOWER: A general power analysis program. Behavior Research Methods, Instruments, \& Computers, 28(1), 1-11. doi:10.3758/bf03203630

Gardner, K. J., Archer, J., \& Jackson, S. (2012). Does maladaptive coping mediate the relationship between borderline personality traits and reactive and proactive aggression?. Aggressive Behavior, 38(5), 403-413. doi:10.1002/ab.21437

Gratz, K. L., Rosenthal, M. Z., Tull, M. T., Lejuez, C. W., \& Gunderson, J. G. (2009). An experimental investigation of emotion dysregulation in borderline personality disorder. Personality Disorders: Theory, Research, and Treatment, S(1), 18-26. doi:10.1037/19492715.s.1.18

Hayes, A. F. (2013). PROCESS: A versatile computational tool for observed variable mediation, moderation, and conditional process modeling. 
Hayes, A. F. (2015). An index and test of linear moderated mediation. Multivariate behavioral research, 50(1), 1-22. doi:10.1080/00273171.2014.962683

Hayes, S. C., Wilson, K. G., Gifford, E. V., Follette, V. M., \& Strosahl, K. (1996). Experiential avoidance and behavioral disorders: A functional dimensional approach to diagnosis and treatment. Journal of Consulting and Clinical Psychology, 64(6), 1152-1168. doi:10.1037/0022-006x.64.6.1152

Hobfoll, S. E. (2014). Stress, social support, and women. Taylor \& Francis.

Hyler, S. E. (1994). Personality diagnostic questionnaire-4. New York: New York State Psychiatric Institute. doi:10.1037/t07759-000

IBM Corp. Released 2017. IBM SPSS Statistics for Windows, Version 25.0. Armonk, NY: IBM Corp.

Javaras, K. N., Zanarini, M. C., Hudson, J. I., Greenfield, S. F., \& Gunderson, J. G. (2017). Functional outcomes in community-based adults with borderline personality disorder. Journal of Psychiatric Research, 89, 105-114. doi:10.1016/j.jpsychires.2017.01.010

Klein, M. H., Benjamin, L. S., Rosenfeld, R., Treece, C., Husted, J., \& Greist, J. H. (1993). The Wisconsin personality disorders inventory: Development, reliability, and validity. Journal of Personality Disorders, 7(4), 285-303. doi:10.1521/pedi.1993.7.4.285

Kosson, D. S., Walsh, Z., Rosenthal, M. Z., \& Lynch, T. R. (2015). Interpersonal Assessment of Borderline Personality Disorder: Preliminary Findings. Journal of Personality Assessment, 97(3), 278-290. doi:10.1080/00223891.2014.983271

Kramer, U., Keller, S., Caspar, F., de Roten, Y., Despland, J. N., \& Kolly, S. (2017). Early change in coping strategies in responsive treatments for borderline personality disorder: 
A mediation analysis. Journal of Consulting and Clinical Psychology, 85(5), 530-535. doi:10.1037/ccp0000196

Kremers, I. P., Spinhoven, P., Van der Does, A. J. W., \& Van Dyck, R. (2006). Social problem solving, autobiographical memory and future specificity in outpatients with borderline personality disorder. Clinical Psychology \& Psychotherapy: An International Journal of Theory \& Practice, 13(2), 131-137. doi:10.1002/cpp.484

Lazarus, S. A., Southward, M. W., \& Cheavens, J. S. (2016). Do borderline personality disorder features and rejection sensitivity predict social network outcomes over time? Personality and Individual Differences, 100, 62-67. doi:10.1016/j.paid.2016.02.032

Linehan, M. M., Bohus, M., \& Lynch, T. R. (2007). Dialectical behavior therapy for pervasive emotion dysregulation: Theoretical and practical underpinnings. In J. J. Gros (Ed.). Handbook of emotion regulation (pp. 581-605). New York, NY: Guildford Press.

Matud, M. P. (2004). Gender differences in stress and coping styles. Personality and individual differences, 37(7), 1401-1415. doi:10.1016/j.paid.2004.01.010

McWilliams, L. A., Cox, B. J., \& Enns, M. W. (2003). Use of the Coping Inventory for Stressful Situations in a clinically depressed sample: Factor structure, personality correlates, and prediction of distress 1. Journal of Clinical Psychology, 59(12), 1371-1385. doi:10.1002/jclp.10228

Millon, T. (1983). Millon Clinical Multiaxial Inventory, MCMI. National Computer Systems, Incorporated.

Narud, K., Mykletun, A., \& Dahl, A. A. (2005). Quality of life in patients with personality disorders seen at an ordinary psychiatric outpatient clinic. BMC Psychiatry, 5(1), 10. doi:10.1186/1471-244x-5-10 
Pereira-Morales, A. J., Adan, A., Lopez-Leon, S., \& Forero, D. A. (2018). Personality traits and health-related quality of life: the mediator role of coping strategies and psychological distress. Annals of General Psychiatry, 17(1), 25. doi:10.1186/s12991-018-0196-0

Ponizovsky, A., Grinshpoon, A., Sasson, R., \& Levav, I. (2004). Stress in adult students with schizophrenia in a supported education program. Comprehensive Psychiatry, 45(5), 401407. doi: 10.1016/j.comppsych.2004.03.012

Ptacek, J. T., Smith, R. E., \& Dodge, K. L. (1994). Gender differences in coping with stress: When stressor and appraisals do not differ. Personality and social psychology bulletin, 20(4), 421-430. doi:10.1177/0146167294204009

Renneberg, B., Herm, K., Hahn, A., Staebler, K., Lammers, C. H., \& Roepke, S. (2012). Perception of social participation in borderline personality disorder. Clinical Psychology \& Psychotherapy, 19(6), 473-480. doi:10.1002/cpp.772

Romero-Canyas, R., Downey, G., Berenson, K., Ayduk, O., \& Kang, N. J. (2010). Rejection sensitivity and the rejection-hostility link in romantic relationships. Journal of Personality, 78(1), 119-148. doi:10.1111/j.1467-6494.2009.00611.x

Rosenbach, C., \& Renneberg, B. (2014). Rejection sensitivity as a mediator of the relationship between experienced rejection and borderline characteristics. Personality and Individual Differences, 69, 176-181. doi:10.1016/j.paid.2014.05.032

Ryan, K., \& Shean, G. (2007). Patterns of interpersonal behaviors and borderline personality characteristics. Personality and Individual Differences, 42(2), 193-200. doi:10.1016/j.paid.2006.06.010

Saklofske, D. H., Austin, E. J., Mastoras, S. M., Beaton, L., \& Osborne, S. E. (2012). Relationships of personality, affect, emotional intelligence and coping with student stress 
and academic success: Different patterns of association for stress and success. Learning and Individual Differences, 22(2), 251-257. doi: 10.1016/j.lindif.2011.02.010

Salz, C. (1983). A theoretical approach to the treatment of work difficulties in borderline personalities. Occupational Therapy in Mental Health, 3(3), 33-46. doi:10.1300/j004v03n03_03

Schaffer, Y., Barak, O., \& Rassovsky, Y. (2015). Social perception in borderline personality disorder: The role of context. Journal of personality disorders, 29(2), 275-288. doi:10.1521/pedi_2013_27_090

Silberschmidt, A., Lee, S., Zanarini, M., \& Schulz, S. C. (2015). Gender differences in borderline personality disorder: results from a multinational, clinical trial sample. Journal of Personality Disorders, 29(6), 828-838.doi:10.1521/pedi_2014_28_175

Skodol, A. E., \& Bender, D. S. (2003). Why Are Women Diagnosed Borderline More Than Men? Psychiatric Quarterly, 74(4), 349-360. doi:10.1023/a:1026087410516

Smith, T. L., Klein, M. H., \& Benjamin, L. S. (2003). Validation of the Wisconsin Personality Disorders Inventory-IV with the SCID-II. Journal of Personality Disorders, 17(3), 173187. doi:10.1521/pedi.17.3.173.22150

Spitzer, M., Fischbacher, U., Herrnberger, B., Grön, G., \& Fehr, E. (2007). The neural signature of social norm compliance. Neuron, 56(1), 185-196. doi:10.1016/j.neuron.2007.09.011

Stepp, S. D., Hallquist, M. N., Morse, J. Q., \& Pilkonis, P. A. (2011). Multimethod investigation of interpersonal functioning in borderline personality disorder. Personality Disorders: Theory, Research, and Treatment, 2(3), 175-192. doi:10.1037/a0020572

Thompson, R. J., Payne, S. C., Horner, M. T., \& Morey, L. C. (2012). Why borderline personality features adversely affect job performance: The role of task 
strategies. Personality and Individual Differences, 52(1), 32-36.

doi:10.1016/j.paid.2011.08.026

Weissman, M. M. (1999). MHS staff. Social adjustment scale-self report (SAS-SR) user's manual. New York: Multi-Health Systems.

Weissman, M. M., \& Bothwell, S. (1976). Assessment of social adjustment by patient selfreport. Archives of general psychiatry, 33(9), 1111-1115.

doi:10.1001/archpsyc. 1976.01770090101010

Zanarini, M. C., Frankenburg, F. R., Dubo, E. D., Sickel, A. E., Trikha, A., Levin, A., \& Reynolds, V. (1998). Axis I comorbidity of borderline personality disorder. American Journal of Psychiatry, 155(12), 1733-1739. doi:10.1176/ajp.155.12.1733

Zanarini, M. C., Frankenburg, F. R., Hennen, J., Reich, D. B., \& Silk, K. R. (2005). Psychosocial functioning of borderline patients and axis II comparison subjects followed prospectively for six years. Journal of Personality Disorders, 19(1), 19-29.

doi:10.1521/pedi.19.1.19.62178

Zielinski, M. J., \& Veilleux, J. C. (2014). Examining the relation between borderline personality features and social support: The mediating role of rejection sensitivity. Personality and Individual Differences, 70, 235-238. doi:10.1016/j.paid.2014.07.005

Zielinski, M. J., \& Veilleux, J. C. (2018). The Perceived Invalidation of Emotion Scale (PIES): Development and psychometric properties of a novel measure of current emotion invalidation. Psychological assessment, 30(11), 1454-1467. doi:10.1037/pas0000584 